\title{
A long-term tree-ring chronology over 796 years for silver fir (Abies alba Mill.) in Southern France
}

\author{
Lisa Shindo $^{1}$ (D) $\cdot$ Christelle Belingard $^{2} \cdot$ Jean-Louis Edouard $^{1} \cdot$ Mélanie Saulnier $^{3}$
}

Received: 20 February 2017 / Accepted: 7 September 2017 /Published online: 9 October 2017

(C) INRA and Springer-Verlag France SAS 2017

\begin{abstract}
- Key message This paper presents ring width data of silver fir trees (Abies alba Mill.) from buildings and living trees from 1214 to 2009 in southeastern France. A 796year chronology spanning the period 1214-2009 has been built. Data can be used for dating projects, paleoecology studies, and climate reconstructions. Dataset access is at https://hal.archives-ouvertes.fr/hal-01528324. Associated metadata is available at https://metadata-afs.nancy.inra. fr/geonetwork/srv/fre/catalog.search\#/metadata/ a74b4869-318c-458c-a5fe-f9ff44a5082c
\end{abstract}

Keywords Abies alba Mill. · Ring width · Dating · Ecology · Climate $\cdot$ Alps $\cdot$ Chronology

\section{Handling Editor: Marianne Peiffer}

Contribution of the co-author

L. Shindo wrote the manuscript. All the authors run the data analysis and reread the paper.

Lisa Shindo

Shindo@mmsh.univ-aix.fr

Christelle Belingard

christelle.belingard@orange.fr

Jean-Louis Edouard

Edouard@mmsh.univ-aix.fr

Mélanie Saulnier

melanie.saulnier@imbe.fr

1 Centre Camille Jullian (UMR CNRS 7269), Aix-en-Provence, France

2 Dtalents and GEOLAB (UMR CNRS 6042), Limoges, France

3 Institut Méditerranéen de Biodiversité et d'Ecologie marine et continentale (UMR CNRS 7263), Aix-en-Provence, France

\section{Background}

The database has 5981 ring widths $(1 / 100 \mathrm{~mm})$ from 515 dated Abies alba Mill. trees and timbers. The area studied is the southeastern France, from Northern Alps (Maurienne) to Southern Pre-Alps (Ventoux), where 31 sites were studied between 1966 and 2015. This included eight buildings (farms, private mansion, and church) and 23 forest stands (Fig. 1). This data was collected during several research projects by six researchers: C. Belingard, J.-L. Edouard, M. Saulnier, F. Serre-Bachet, L. Shindo, and L. Tessier from Aix-enProvence and Marseille. Until now, this data had not been published in one source.

Here is their acquisition context: Maurienne sites were studied as part of a research program on fluorinated pollution on trees radial growth (Tessier et al. 1990); F. Serre-Bachet studied Verdon Abies alba Mill. and created a long master chronology in order to work on climate reconstructions (Serre-Bachet 1986); Mercantour and Verdon Abies alba Mill. were part of a program on climate and tree-ring relations in IMEP/IMBE laboratory (European program FORMAT edited by L. Tessier and J.-L. Edouard, Belingard 1996, Saulnier 2012) and research on Aix-en-Provence and Riez ancient buildings (Edouard, unpublished reports, Shindo 2016).

\section{Method}

\subsection{Definitions}

- Average growth chronology: "chronology averages from all the growth curves within a tree or a piece of timber." (Kaennel and Schweingruber 1995, p.35). Here, we use this term to qualify archaeological site chronologies made with only one timber 
Fig. 1 Location of the 31 studied sites (map: geoportail.fr)

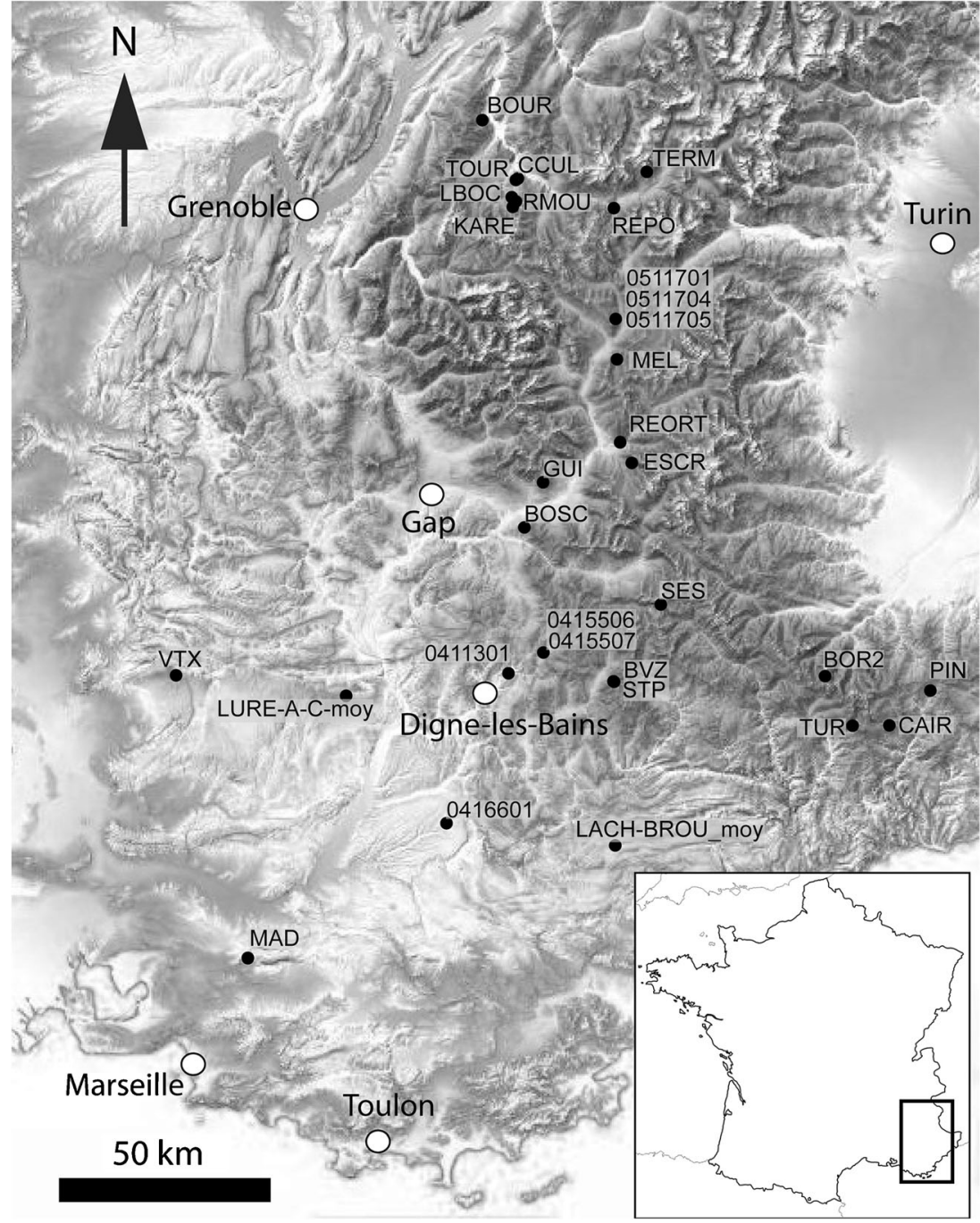

(three sites are concerned, see "Dataset content" section below). Several radii were measured and averaged on these timbers.

- Site chronology: "Chronology averaged from raw tree-ring measurements or standardised indices for one to several cores per tree and for several trees growing on similar types of (ecological) sites." (Kaennel and Schweingruber 1995, p.316). Here, there are 31 sites; therefore, there are 31 site chronologies. That means that the three "average growth chronologies" are "site chronologies" too because they are representative of these three sites.

- Master chronology: "Chronology averaged from any tree-ring parameter, usually combining site or local chronologies from a given region, and used to date new tree-ring series." (Kaennel and Schweingruber 1995, p.217). Here, the master chronology is the average of the 515 dated Abies alba Mill. trees and timbers and covers 796 years, from 1214 to 2009.

\subsection{Sampling}

The methods used to obtain the samples are typical for dendrochronology. Different sampling techniques were required for the living trees and the timbers. Living trees were cored with Pressler increment borers at breast height (around $1.30 \mathrm{~m}$ above the ground). The timbers were sampled utilising one of the three different techniques with Pressler increment borers, with a borer on an electric drill and sometimes, when possible, the timbers were cut with a saw. In the case of the timbers, the sample area was strategically selected in order to obtain the largest amount of tree-rings as close as possible to the bark. Nevertheless, due to the building layout, it was not always possible to do this. Thus, the sampling was carried out on the only accessible location of the timber.

\subsection{Measurement and cross-dating}

In the lab, ring widths were measured using the incremental measuring table LINTAB with $0.01 \mathrm{~mm}$ accuracy and TSAP- 


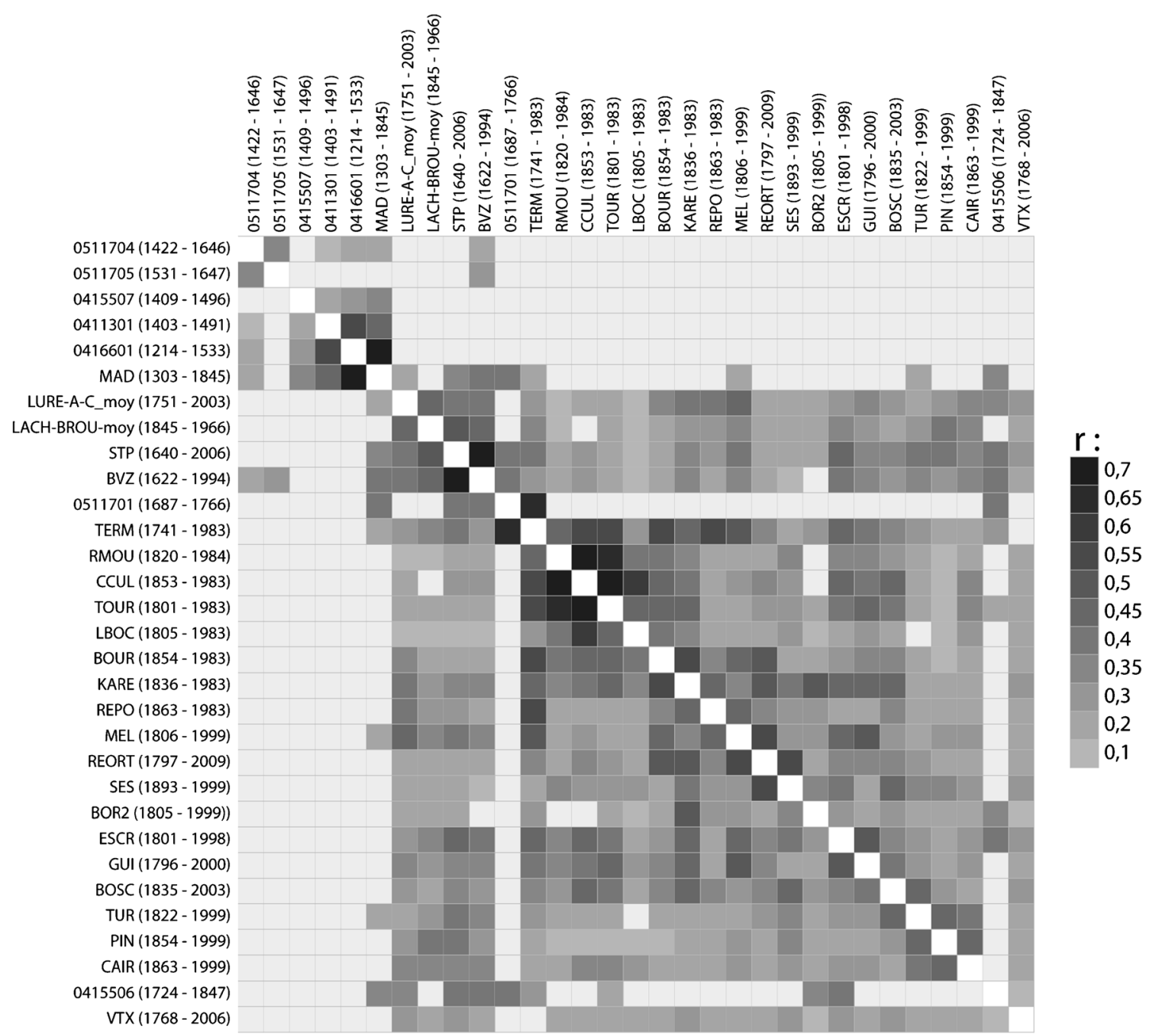

Fig. 2 Square matrix of correlation coefficient ( $r$ ) for the 31 correlated Abies alba Mill. site chronologies (standardised by the Corridor method (Lambert 2006)). The darker is the box, the higher is the correlation between the site series (matrix automatically drawn by Dendron IV software Lambert 2014)

Win software (Rinntech Company, Heidelberg, Deutschland). Then, the tree-ring series were cross-dated. Cross-dating is "the procedure of matching variations in ring width $[\ldots]$ among several tree-ring series" (Kaennel and Schweingruber 1995, p.81). Cross-dating was carried out by means of TSAPWin software, COFECHA software (written in Fortran-77, Holmes 1983), or DENDRON IV software (developed with RunRev LiveCode, Edinburgh, Scotland, by G.-N. Lambert CNRS, University of Franche-Comté, Besançon, France and University of Liege, Belgium. Version: 20150221). For living trees, their various acquisition contexts caused a regrettable lack of uniformity into ecological condition information available (height of sampling, soil type, type of forest...).

\subsection{Dataset content}

The database is in a spreadsheet format with three sections (Shindo et al. 2017). The first spreadsheet in the database, labelled, "material description", includes the following information: site dendrochronological code, the type of site (building or living trees), the geographic coordinates (longitude and latitude in WGS 84), the site altitude, the town and the geographical area, the author, the beginning, the end, the length, and the volume of the site chronologies.

The second spreadsheet, "sites_chronologies_data", presents the dendrochronological raw data $(1 / 100 \mathrm{~mm})$ of the 31 sites without any standardisation. The first column in the spreadsheet is the site code, the second column is the time scale, the third column includes the ring width $(1 / 100 \mathrm{~mm})$, and the fourth column is the volume of the site chronology (number of tree-rings per year). Three of the sites (0411301, 0415506, 0511701) only have an average growth chronology because only one Abies alba Mill. timber has been dated for each of these sites. We chose to present them as they are representative of the site and are good dating tools. F. SerreBachet studied Ventoux living trees data ("FRAN7" in the 
master chronology: $1 / 100 \mathrm{~mm}$

volume curve: number of tree-rings per year

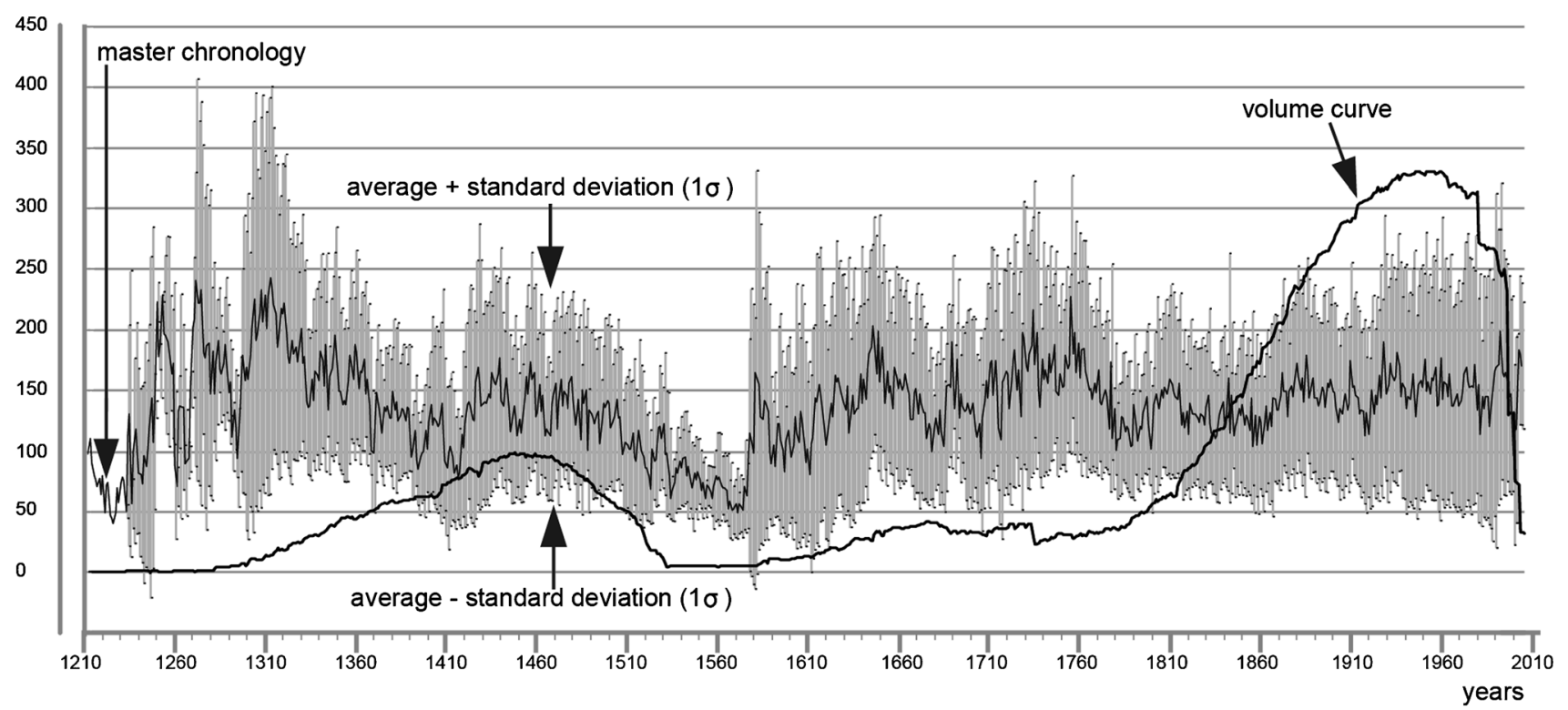

Fig. 3 Master chronology of the 515 individual series between 1214 and 2009. The standard deviations $(1 \sigma)$ are represented for each year (average plus standard deviation and average minus standard deviation) as well as the master chronology volume (the maximum is in the second part of the twentieth century: maximum 332 individuals per year)
International Tree-Rings Database, ITRDB, https://www. ncdc.noaa.gov/data-access/paleoclimatology-data/datasets/ tree-ring) that come from the same site than our "VTX" site chronology but are not included in our database yet.

The third and last spreadsheet, "master_chronology_data", gives the ring width $(1 / 100 \mathrm{~mm})$ of this master chronology from 1214 to 2009 its volume and its standard deviation $(1 \sigma)$.

\subsubsection{Access to data and metadata description}

The URL to access the dataset is located in https://hal. archives-ouvertes.fr/hal-01528324. Associated metadata is available at https://metadata-afs.nancy.inra.fr/geonetwork/ srv/fre/catalog.search\#/metadata/a74b4869-318c-458c-a5fef9ff44a5082c. The data, which includes the calculations, can be used; however, you must attribute their origin (licence CC BY-NC 4.0).

The individual contact details of the six researchers are presented but three of the researchers are not in activity anymore. If complementary data is necessary, the corresponding author should be contacted.

\subsubsection{Technical validation}

The dataset has already been utilised for ecological studies and climate reconstructions. Published works utilising this data include research by Saulnier (2012), Serre-Bachet (1986), and Tessier et al. (1990). Furthermore, this master chronology is a very good tool for dating wood building structures as silver fir timber was commonly used in construction. Indeed, many constructions were built with silver fir timbers and the tree felling was precisely dated, in particular in Bouches-du-Rhône, Alpes-de-Haute-Provence, and Hautes-Alpes French departments (Shindo 2016).

\subsubsection{Reuse potential and limits}

Some years, the average standard deviation is particularly high (Fig. 3) even if the master chronology volume is important. For example, in 1430, there is a number of 80 tree-rings and the average standard deviation is 118 . This could be due to the presence at the same year of wide and narrow tree-rings from young and old trees.

The relation between each site chronology can be presented in a symmetrical square chart, a correlation matrix, "that compares and shows correlations obtained from all of the different possible pairs" (Lambert 2011, p.26). In our matrix (Fig. 2), we can make out two groups. The first group, in the upper left corner, contains the six oldest site chronologies. The second group is composed of 26 site chronologies; these are the most recent site chronologies. The MAD chronology makes the link between the two groups. In each group, the probability is high from Northern Alps (Maurienne) to Southern Pre-Alps (Ventoux). Abies alba Mill. presents good correlations even at long distance (Fig. 2).

The potential use of this new database is numerous. It can serve to date Abies alba Mill. timbers from the Southeast 
France and, thanks to its good correlations, samples from other areas may be dated too.

In addition to dating projects, Abies alba Mill. paleoecology could be studied up to 1214 (date of the oldest tree-ring measured). The data is particularly significant between 1369 and 1514 and 1796-2003, time period for which the volume is important (there are more than 50 ring widths each year) (Fig. 3).

It could act as an incentive to inter-species correlation studies, for example, on Abies alba Mill., Picea abies L., and Larix decidua Mill. in order to highlight a shared climatologic signal (we are developing a project on this subject).

This data paper is one of the only ways to ensure permanence of the dendrochronological data and metadata and to make them widely circulate. We hope that new research will be made on these data, for example, on Abies alba Mill. ecology and on climatology. In the end, this database may be improved and it is a stimulating tool for partnership.

Acknowledgements The authors are grateful to Gina Watkinson of the Arizona State Museum (USA) for her help regarding the translation.

\section{References}

Belingard C (1996) Etude dendroécologique de la dynamique de la limite supérieure de la forêt dans les Alpes du sud, en relation avec les facteurs climatique et anthropique. Dissertation, University of AixMarseille, pp 103

Holmes R-L (1983) Computer-assisted quality control in tree-ring dating and measurement. Tree-Ring Bull 43:69-75

Kaennel M, Schweigruber F-H (1995) Multilingual glossary of dendrochronology. Terms and definitions in English, German, French, Spanish, Italian and Russian, Paul Haupt, Bern, pp 467

Lambert G-N (2006) Dendrochronologie, histoire et archéologie, modélisation du temps. Le logiciel Dendron II et le projet Historik Oaks, V1 et V2, Habilitation à diriger les recherches, Besançon. Dissertation, University of Franche-Comté

Lambert G-N (2011) Dendrochronology, archaeology and sciences. In Fraiture $\mathrm{P}$ (ed) Tree rings, art, archaeology, proceedings of the conference, Brussels, Royal Institute for Cultural Heritage, 10-12 February 2010, Scientia Artis 7, Brussels, pp 19-29

Serre-Bachet F (1986) Une chronologie maitresse du sapin (Abies alba Mill.) du Mont Ventoux. Dendrochronologia 4:87-96

Saulnier M (2012) Histoire et dynamique de la forêt subalpine dans le Alpes du Sud (Briançonnais, Queyras): approches pédoanthracologique et dendrochronologique. Dissertation, AixMarseille University, pp 288

Shindo L (2016) Bois de construction et ressources forestières dans les Alpes du sud au IIe millénaire. Dendrochrono-écologie et archéologie. Dissertation, Aix-Marseille University, pp 935 (on line: https://hal-sde.archives-ouvertes.fr/tel-01325760/)

Shindo L, Belingard C, Edouard JL, Saulnier M (2017): A long-term treering chronology over 796 years for silver fir (Abies alba Mill.) in southern France. On line only: https://hal.archives-ouvertes.fr/hal01528324

Tessier L, Serre-Bachet F, Guiot J (1990) Pollution fluorée et croissance radiale des conifères en Maurienne (Savoie, France). Ann Sci For 47:309-323 